\title{
GERMINAÇÃO DE SEMENTES DE MILHETO (Pennisetum glaucum (L.) R. Br.) SOB STRESS SALINO
}

\author{
Gustavo Pereira Valani ${ }^{1}$ \\ Arthur Barros Ziviani² \\ Eduardo Cesana Júnior ${ }^{3}$ \\ Moises Zucoloto ${ }^{4}$
}

Resumo - O presente trabalho teve como objetivo avaliar a germinação e o índice de velocidade de germinação em sementes de milheto (Pennisetum glaucum (L.) R. Br.) da variedade BRS 1501 submetido a diferentes concentrações salinas em duas faixas de temperaturas. As sementes foram submetidas em solução de $\mathrm{NaCl}$ a 0, 25, 50 e $100 \mathrm{mM}$ e nas temperaturas 20oC e 18/24oC, com quatro repetições e vinte e cinco sementes por repetição. A porcentagem de germinação e o IVG não diferiram significativamente entre os tratamentos e nem sobre as diferentes temperaturas avaliadas, possivelmente devido a tolerância do milheto ao stress salino. É necessário, contudo, estudar o efeito do estresse salino em estádios pósgerminativos.

Palavras-chave: Pennisetum glaucum; Salinidade; Cloreto de sódio.

\footnotetext{
${ }_{1}$ Agronomia/Universidade Federal do Espírito Santo, Brasil. gustavo.valani@hotmail.com.

2 Agronomia/Universidade Federal do Espírito Santo, Brasil. arthurbarrosziviani@hotmail.com.

3 Agronomia/Universidade Federal do Espírito Santo, Brasil. eduardo.cesana@hotmail.com.

${ }^{4}$ Agronomia/Universidade Federal do Espírito Santo, Brasil. moiseszucoloto@hotmail.com.
} 